\title{
GERAÇÃo de MOdELOS dE REGIONALIZAÇÃo dE VAZÕES MÁXIMAS, MÉDIAS DE LONGO PERÍOdO E MíNIMAS DE SETE dias para a bacia do RIO do Carmo, Minas Gerais
}

\section{Models generation OF REgIONALIZATION OF MAXIMUM, MEDIUM AND MINIMUM OF SEVEN DAYS FLOW RATES FOR THE CARMO RIVER basin, Minas Gerais}

\author{
SYLVIO ELVIS DA SILVA BARBOSA \\ Mestrando em Engenharia Ambiental - Pró-Água - UFOP
}

ANTENOR RODRIGUES BARBOSA JÚNIOR

Doutor em Engenharia Civil pela Escola de Engenharia de São Carlos - USP. Professor do Departamento de Engenharia Civil da Escola de Minas - UFOP

\section{GILBERTo QUEIROZ DA SILVA}

Mestre em Hidráulica e Saneamento pela Escola de Engenharia de São Carlos - USP. Professor do Departamentos de Engenharia Civil da Escola de Minas - UFOP

\section{ELIZABETH NEVES BORGES CAMPOS}

Engenheira Civil pela Escola de Minas - UFOP

VANESSA DE CARVALHO RODRIGUES

Engenheira Civil pela Escola de Minas - UFOP

\author{
Recebido: 18/05/04 Aceito: 08/09/04
}

\section{RESUMO}

O fato de ser limitada a disponibilidade hídrica de uma bacia hidrográfica, aliado ao crescente aumento da demanda motivado pelos mais variados usos e impulsionado pelo desenvolvimento econômico, exige a adoção de critérios de gestão capazes de minimizar os inevitáveis conflitos pelo uso da água. Para que a gestão seja adequada, requer-se o conhecimento dos diferentes segmentos do ciclo hidrológico, notadamente da precipitação e da vazão. Com isso, e considerando-se a importância de se verem atendidas as regióes com ausência ou escassez de dados fluviométricos, desenvolveu-se o presente estudo de construção de modelos matemáticos de regionalização de vazões na bacia do rio do Carmo. Para isso, foram construídas as séries de chuvas totais anuais, totais do semestre mais chuvoso e máximas diárias, e as séries de vazōes máximas, médias e mínimas. As séries de chuvas no ponto foram convertidas em chuvas na área com o uso do método de Thiessen. Com base nas séries anuais das vazões máximas, médias e mínimas, ajustaram-se modelos de probabilidade que permitiram a extrapolação dos dados históricos. Ainda, para pesquisar a influência do relevo sobre as variáveis hidrológicas foram feitas as quantificaçōes de diferentes parâmetros que caracterizam a bacia. Deste modo, ao final foram construídos os modelos de regionalização das vazões.

PALAVRAS-CHAVE: Regionalização hidrológica, vazão fluvial, recursos hídricos superficiais, bacia hidrográfica.

\section{ABSTRACT}

In a watershed, the water resources are limited. That fact and the increase of the demand due to the several uses and impelled by the economic development requests the adoption of administration approaches that minimizes the conflicts for the use of water. For an appropriate administration, it is necessary to know the different segments of the hydrologic cycle, mainly the rain and the flow. Considered the importance of these data in the areas with absence or shortage of streamflow gaging data, the present study was developed for the construction of regional regression equation for estimating flow characteristics for streams in Carmo River basin. For that, the series of annual total rain, total of the rainiest semester, maximum daily rain and maximum, medium and minimum flow rates were built. The punctual rains were transformed in rains in the area according to Thiessen method. Models of probability were adjusted starting from maximum, medium and minimum flow rates, and allowing to extrapolate historical data. The different parameters that characterize the basin were quantified to research the influence of the relief on the bydrologic variables. Finally, the regional flow rates equations were generated.

KEYWORDS: Hydrologic regionalization, stream discharge, surface water resources, watershed. 


\section{INTRODUÇÃO}

O planejamento, projeto e operação de qualquer obra relacionada com o aproveitamento, controle e proteção dos recursos hídricos em uma bacia hidrográfica baseiam-se na avaliação da demanda frente à disponibilidade de água na bacia. Para uma gestão adequada, notadamente nas atividades de administração, a disponibilidade hídrica na bacia precisa ser bem conhecida. Essa disponibilidade é avaliada através da aplicação de um balanço hídrico, para o que é imprescindível o conhecimento das principais variáveis hidrológicas, notadamente da precipitação e da vazão.

Conhecer a precipitação é a forma de quantificar a entrada de água na bacia hidrográfica, enquanto o conhecimento das vazóes máximas, médias e mínimas permite, entre outras aplicaçôes, projetar obras hidráulicas e auxiliar nos processos de outorga do direito de uso da água.

Como forma de conhecer a relação demanda-disponibilidade, é preciso quantificar a vazão média de longo período. Essa vazão média dá uma indicação do potencial energético da bacia hidrográfica e representa a maior vazão passível de ser regularizada. Ela entra no cálculo do volume de regularização quando se projeta a construção de um reservatório.

Complementarmente, na avaliação da disponibilidade natural dos cursos d'água, para se tomar decisão sobre a necessidade ou não de regularização artificial, para os projetos de irrigação e de aproveitamento hidrelétrico, para os estudos envolvendo a capacidade natural de autodepuração do curso d'água e, também, para avaliar a possibilidade de concessão do uso da água para uma dada finalidade, é fundamental o conhecimento das vazões mínimas, que são caracterizadas pela duração e freqüência (ou período de retorno).

A vazão máxima, que também é caracterizada pela freqüência da sua ocorrência, está particularmente associada aos riscos de inundação em uma bacia e à definição das vazões de projeto de obras hidráulicas de controle de enchentes. Ela é utilizada nos estudos voltados para os projetos dos vertedores de barragens, dos canais de drenagem, dos bueiros e galerias de águas pluviais, dos diques e dos vãos de pontes, entre outros.

Objetivando a regionalização, o tratamento das variáveis hidrológicas iniciase pelos registros diários das quantidades chuva e vazão em estações pluviométricas e fluviométricas da bacia do rio do Carmo, a partir dos quais são construídas as séries históricas anuais dessas variáveis que, com o uso de modelos de probabilidade apropriados, permitem estimar as freqüências das ocorrências das mesmas ao longo do tempo.

\section{Regionalização de vazões}

Em estudos do aproveitamento dos recursos hídricos de uma bacia hidrográfica defronta-se, muitas vezes, com o problema da ausência ou insuficiência de dados que permitam a construção da série histórica de vazóes, necessária à avaliação da disponibilidade hídrica superficial. Nesses casos, requer-se a aplicação de técnicas de transferência de informaçôes de outros locais climaticamente semelhantes para a bacia hidrográfica em questão. Ao procedimento de transferência de informações de vazão denomina-se regionalização.

Entende-se por regionalização hidrológica, ou mais especificamente regionalização de vazões, o conjunto de procedimentos e métodos estatísticos que visam explorar ao máximo os dados existentes numa região, buscando-se permitir a estimativa da vazão num local com ausência ou insuficiência de dados. Por meio da regionalização, visa-se permitir, por exemplo, a obtenção indireta das vazões em seções em que faltem dados ou onde, por fatores de ordem física ou econômica, não seja possível a instalação de estaçôes hidrométricas. A estimativa é realizada com base em modelos de cálculo das vazões, que se demonstram estatisticamente aplicáveis a qualquer seção fluvial da bacia considerada.

Em geral, o modelo de regionalização considera as características físicas e/ou climáticas da bacia que exercem maior importância em seu comportamento hidrológico, características essas que são levadas em conta com diferentes pesos na regressão. Enquanto a precipitação média, o total anual ou o total do semestre mais chuvoso são normalmente empregados como variável independente para representar o efeito do clima, as características físicas que entram como variáveis independentes são a área de drenagem, o comprimento e a declividade do curso d'água principal e a densidade de drenagem. Esses elementos de natureza física são de grande importância no comportamento hidrológico da bacia hidrográfica, e são introduzidos no modelo de regionalização por explicarem a distribuição espacial da vazão e pela sua estreita correspondência com o regime hidrológico da região.

\section{A bacia hidrográfica do rio do Carmo}

O rio do Carmo pertence à bacia hidrográfica do rio Doce (alto rio Doce), que se situa na região Sudeste brasileira.

A bacia do rio do Carmo, conforme obtido neste estudo, apresenta uma área de drenagem de $2.279 \mathrm{~km}^{2}$, que equivale a $2,73 \%$ da bacia do rio Doce (esquema ilustrativo na Figura 1). Localiza-se integralmente no estado de Minas Gerais e tem como coordenadas extremas, respectivamente: ao norte e ao sul, os paralelos de 2009' 59,04 "S e $20^{\circ} 36$ '47,88”'S; e a oeste a leste, os meridianos 4342' $5,04^{\prime \prime} \mathrm{W}$ e 42 54 '47,16"W. A regiāo abrange cerca de 14 municípios, localizados total ou parcialmente dentro da bacia. Estes municípios possuem, no total, cerca de 278.000 habitantes, segundo estimativa do IBGE para o ano de 2000 .

O rio do Carmo corre por uma extensão de $134 \mathrm{~km}$ e, junto à cabeceira, no município de Ouro Preto, tem como principais formadores o ribeirão do Funil e o córrego do Tripuí, que nascem na Serra do Veloso. Sua foz encontra-se no município de Rio Doce, na confluência com o rio Piranga, quando formam o rio Doce. Entre seus afluentes destacam-se, pelo porte, os rios Gualaxo do Norte, pela margem esquerda, e Gualaxo do Sul, pela margem direita.

Quanto à vegetação, na área abrangida pela bacia, os aspectos florais atuais refletem a atuação antrópica do homem sobre o meio natural. Estes aspectos apresentam-se sob a forma de uma paisagem combinada de pastagens e capoeira, com predominância da primeira na metade leste e da segunda na parte ocidental da área. Verifica-se, também, que em vários locais a vegetação nativa vem sendo substituída pelo reflorestamento com eucalipto, (Projeto Radambrasil,1983).

\section{METODOLOGIA}

Na primeira etapa deste estudo voltado para a regionalização de vazóes, foram utilizadas 11 cartas topográficas do IBGE, em escala 1:50.000, com curvas de nível de 20 em 20 metros, que foram digitalizadas na área que cobre a bacia do rio do Carmo. $\mathrm{Na}$ ausência de mesa 


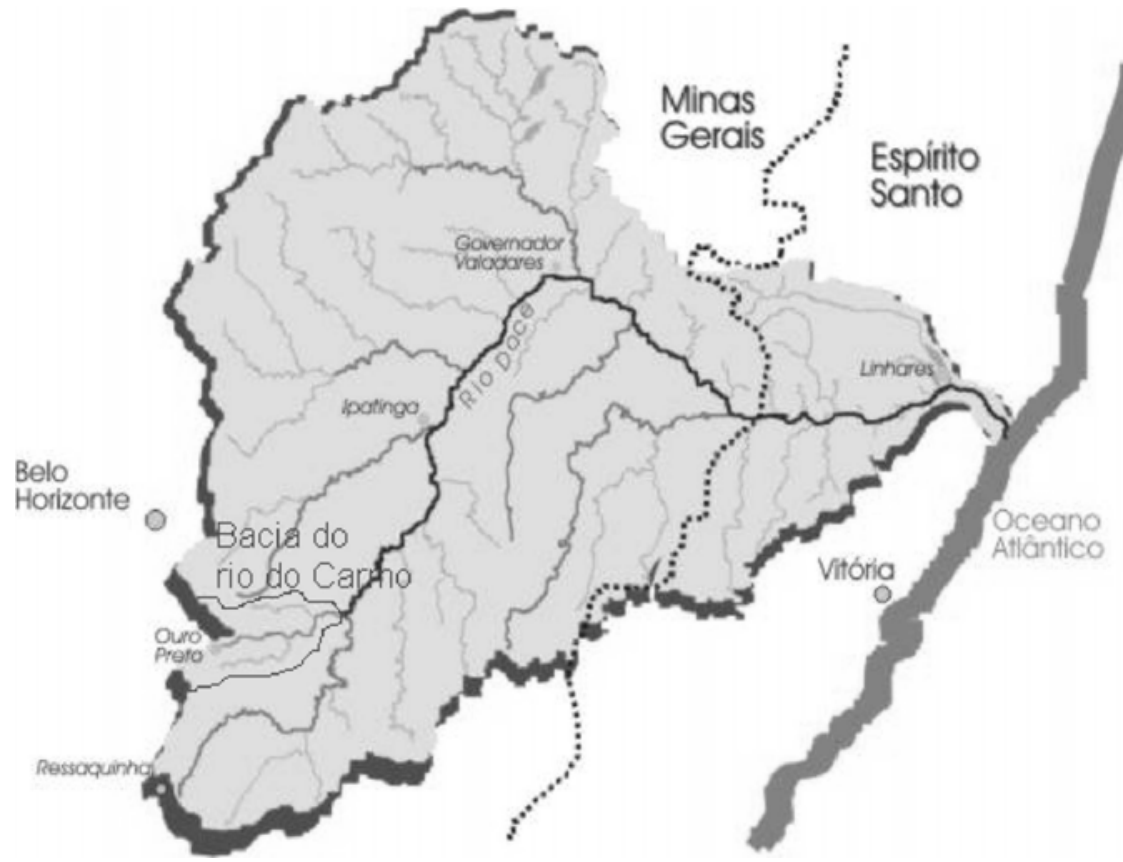

Figura I - Mapa ilustrativo da bacia do rio Doce e da bacia do rio do Carmo, realização comitê da bacia hidrográfica do rio Doce

digitalizadora, para a geração do mapa digital as cartas topográficas foram divididas em regiōes de $6 \mathrm{~km} \times 6 \mathrm{~km}$, que foram scannerizadas. Uma dimensão assim tão pequena serviu para minimizar a distorção provocada pelo scanner.

Numa etapa seguinte, a articulação das cartas foi dividida em duas regiôes pelo meridiano $43^{\circ} 17^{\prime} 48,65^{\prime \prime}$. Para cada região, com o uso do programa computacional GEOMAP, foi gerada uma malha quadriculada de tamanho $2 \mathrm{~km} \mathrm{x}$ $2 \mathrm{~km}$, em coordenadas UTM, devidamente geo-referenciada. Tendo como base esta malha, com a ajuda do programa AutoCAD Map 2000, as figuras scannerizadas foram inseridas uma a uma através do ajuste de suas coordenadas UTM às da malha correspondente.

Paralelamente à etapa anterior, foram processados os dados hidrológicos brutos de chuva e vazão obtidos do banco de dados da ANEEL (Agência Nacional de Água e Energia Elétrica), bem como alguns dados de chuva de estações monitoradas pela empresa ALCAN - Alumínio do Brasil (Santos e Barbosa Jr., 1999).

Uma pesquisa preliminar foi realizada com a base de dados de chuva e vazão da bacia do rio do Carmo e sua vizinhança para se avaliar as estaçôes úteis para a regionalização. Utilizando-se de diagramas de barra de 25 estações
Visando a regionalização, as chuvas pontuais foram convertidas em chuvas espaciais. No cálculo das precipitações médias espaciais nas sub-bacias que compõem a bacia do rio do Carmo, foi usado o método de Thiessen. As médias espaciais do total anual, do total do semestre mais chuvoso e da chuva máxima diária foram calculadas eletronicamente, com o emprego de um módulo especial do programa computacional RH3.0 (Euclydes et al, 1999). Nesse módulo exigem-se as coordenadas geográficas dos vértices dos polígonos que definem a área total da bacia, bem como os vértices dos polígonos que definem cada uma das sub-bacias, além das coordenadas geográficas de cada estação pluviométrica. Os vértices das áreas envolvidas foram informados através de um arquivo DXF, obtido a partir do mapa da bacia previamente digitalizado com o uso do programa computacional AutoCAD Map 2000.

\section{RESULTADOS}

Na Tabela 1, estão relacionados os resultados encontrados para as médias espaciais das chuvas total anual, total do semestre mais chuvoso e máxima diária, para todas as sub-bacias definidas pelas estações fluviométricas da bacia do rio do Carmo. Na última linha desta tabela, são informados os resultados das médias espaciais sobre toda bacia do rio do Carmo, para cada um dos tipos de séries anuais.

Considerando-se o tamanho da bacia e o pequeno número de estações fluviométricas úteis para a regionalização, toda a bacia foi considerada como uma única região homogênea. Esta hipótese foi bem confirmada pela verificação de que são praticamente idênticas as distribuições das freqüências das vazôes adimensionalizadas médias, máximas e mínimas para as quatro estações fluviométricas.

De posse das séries de dados de chuva e vazão e do conjunto de parâmetros que caracterizam fisicamente as sub-bacias associadas às estações fluviométricas, procedeu-se à regionalização das vazôes com a construçáo de modelos matemáticos baseados em regressóes não lineares para as máximas, mínimas e médias de várias recorrências entre 2 e 100 anos.

\section{Caracterização física da bacia}

A caracterização física da bacia hidrográfica do rio do Carmo é justificada 
por ser uma possibilidade bastante conveniente de se conhecer a variação no espaço das grandezas relacionadas ao regime hidrológico da região (Barbosa et. al, 2002). Os elementos de natureza física possibilitam o estabelecimento de relaçôes e comparações entre a fisiografia e os dados hidrológicos conhecidos.

Os levantamentos quantitativos da fisiografia da bacia foram feitos a partir da versão digitalizada do mapa topográfico. Tendo em vista a regionalização, na caracterização fisiográfica da bacia foram determinados as áreas de drenagem, os comprimentos de talvegues, as densidade de drenagem e as declividade dos cursos d'água principais, tanto para a bacia do rio do Carmo como um todo, quanto para as quatro sub-bacias associadas às estaçôes fluviométricas.

Na Tabela 2 apresentam-se os resultados em termos dos parâmetros físicos que caracterizam as sub-bacias associadas às estaçôes fluviométricas da bacia do rio do Carmo e a própria bacia como um todo. Cada uma das estaçôes tem suas coordenadas apresentadas na Tabela 3, juntamente com o seu código ANEEL.

Os parâmetros físicos foram determinados a partir do processamento eletrônico da imagem digital da bacia, apoiando-se no uso de programa computacional em Cad.

\section{Modelos de Regionalização}

Para pesquisar a distribuição de probabilidade que melhor representa os eventos máximos, médios e mínimos foram testados os modelos teóricos de Gumbel, Normal, Log-Normal, Pearson tipo III, Log-Pearson tipo III e Weibull, sendo a escolha da distribuição mais significativa feita segundo o teste de KolmogorovSmirnov, buscando-se ainda o menor coeficiente de variação.

No caso das vazões médias e mínimas, a distribuição de Weibull foi a que apresentou os melhores ajustes, além de atender aos critérios de significância pelo método de Kolmogorov-Smirnov e coeficiente de variação. Já para as máximas, foi a distribuição de probabilidade Pearson tipo III que apresentou os melhores ajustes.

Para cada uma das 4 estações fluviométricas, com base na distribuição Weibull para as médias e mínimas, e com base na distribuição Pearson tipo III para as máximas, foram obtidos os valores das correspondentes vazões de diferentes recorrências: 2, 5, 10, 20, 50 e 100 anos,

Tabela I - Resultados obtidos pela aplicação do método de Thiessen para o cálculo das médias espaciais das precipitações total anual, total do semestre mais chuvoso e máxima diária, para as quatro sub-bacias e para toda a bacia do rio do Carmo

\begin{tabular}{cccccc}
\hline $\begin{array}{c}\text { Código } \\
\text { ANEEL }\end{array}$ & Estação Fluviométrica & Curso d'água & \multicolumn{3}{c}{ Precipitação (mm) } \\
& & & $\begin{array}{c}\text { Total } \\
\text { anual }\end{array}$ & $\begin{array}{c}\text { Sem. + } \\
\text { chuvoso }\end{array}$ & diáría \\
\hline 56170000 & Vargem do Tijucal & $\begin{array}{c}\text { Ribeirão da } \\
\text { Cachoeira }\end{array}$ & 1282,70 & 1096,60 & 71,80 \\
56240000 & Fazenda Paraíso & Gualaxo do Sul & 1145,30 & 1233,60 & 74,80 \\
56335001 & Acaiaca-Jusante & Rio do Carmo & 1471,80 & 1286,90 & 78,70 \\
56337000 & Fazenda Ocidente & Gualaxo do Norte & 1536,90 & 1304,30 & 84,90 \\
--- & Bacia do rio do Carmo & --- & 1471,50 & 1275,10 & 79,90 \\
\hline
\end{tabular}

Tabela 2 - Parâmetros que caracterizam fisicamente as sub-bacias e a bacia do rio do Carmo

\begin{tabular}{|c|c|c|c|c|c|}
\hline Sub-bacia & Curso d'água & $\begin{array}{c}\text { Área de } \\
\text { drenagem } \\
\left(\mathrm{Km}^{2}\right)\end{array}$ & $\begin{array}{c}\text { Drenagem } \\
\text { total } \\
(\mathrm{Km})\end{array}$ & $\begin{array}{c}\text { Densidade } \\
\text { de drenagem } \\
\left(\mathrm{Km}^{-1}\right)\end{array}$ & $\begin{array}{c}\text { Comprimento } \\
\text { axial } \\
(\mathrm{Km})\end{array}$ \\
\hline $\begin{array}{c}\text { Estação Fluv. } \\
\text { Fazenda Ocidente }\end{array}$ & $\begin{array}{l}\text { Gualaxo do } \\
\text { Norte }\end{array}$ & 527,098 & 1337,81 & 2,54 & 79,409 \\
\hline $\begin{array}{l}\text { Estação Fluv. } \\
\text { Acaiaca-Jusante }\end{array}$ & $\begin{array}{l}\text { Rio do } \\
\text { Carmo }\end{array}$ & 1334,223 & 3133,96 & 2,35 & 79,896 \\
\hline $\begin{array}{l}\text { Estação Fluv. } \\
\text { Fazenda Paraíso }\end{array}$ & $\begin{array}{l}\text { Gualaxo do } \\
\text { Sul }\end{array}$ & 856,544 & 2061,24 & 2,41 & 101,461 \\
\hline $\begin{array}{c}\text { Estação Fluv. } \\
\text { Vargem do Tijucal }\end{array}$ & $\begin{array}{l}\text { Ribeirão da } \\
\text { Cachoeira }\end{array}$ & 225,316 & 534,96 & 2,37 & 28,442 \\
\hline Bacia do rio do Carmo & --- & 2279,213 & 5538,05 & 2,43 & 132,340 \\
\hline
\end{tabular}

Tabela 3 - Coordenadas e código ANEEL para as estações fluviométricas da bacia do rio do Carmo

\begin{tabular}{cccc}
\hline Estação & Código ANEEL & \multicolumn{2}{c}{ Coordenadas } \\
& & Latitude & Longitude \\
\hline Fazenda Ocidente & 56337000 & $-20^{\circ} 17^{\prime} 08^{\prime \prime}$ & $-43^{\circ} 05^{\prime} 56^{\prime \prime}$ \\
Acaiaca-Jusante & 56335001 & $-20^{\circ} 21^{\prime} 45^{\prime \prime}$ & $-43^{\circ} 08^{\prime} 38^{\prime \prime}$ \\
Fazenda Paraíso & 56240000 & $-20^{\circ} 22^{\prime} 37^{\prime \prime}$ & $-43^{\circ} 11^{\prime} 31^{\prime \prime}$ \\
Vargem do Tijucal & 56170000 & $-20^{\circ} 29^{\prime} 00^{\prime \prime}$ & $-43^{\circ} 33^{\prime} 00^{\prime \prime}$ \\
\hline
\end{tabular}

para as médias e mínimas e 2, 10, 20, 50, 100 e 500 anos para as máximas. A título de ilustração, e para mostrar a qualidade das previsões produzidas pelos modelos de probabilidade, nas Figuras 2, 3 e 4 são apresentados gráficos de freqüência característicos, onde se superpõem à série histórica as curvas que representam os melhores modelos de probabilidade ajustados aos dados de vazões mínimas, máximas e médias, respectivamente. Nessas figuras, foram considerados os dados relativos à estação Acaiaca-Jusante (vazôes $\mathrm{em} \mathrm{m}^{3} / \mathrm{s}$ nas ordenadas).

Seguindo os procedimentos adotados em Euclydes et al, 2001 e Tucci,
1997, a análise de regressão foi utilizada para investigar como a vazão de determinada recorrência era afetada pelas variáveis independentes, postas em termos das características físicas e climáticas da bacia. A função matemática utilizada para relacionar as variáveis foi escrita na forma

$$
\mathrm{q}_{\mathrm{Tr}}=\mathrm{f}\left(\mathrm{A}, \mathrm{L}, \mathrm{D}, \mathrm{S}, \mathrm{P}_{\text {tot }}, \mathrm{P}_{\text {máx }}, \mathrm{P}_{\text {sem+ch }}\right)
$$

onde:

$\mathrm{q}_{\mathrm{tr}}$ = vazão específica de recorrência $\mathrm{Tr}$, medida pela razão da vazão $\mathrm{Q}_{\mathrm{Tr}}$ pela área de drenagem; $\mathrm{A}=$ área de drenagem da bacia; 


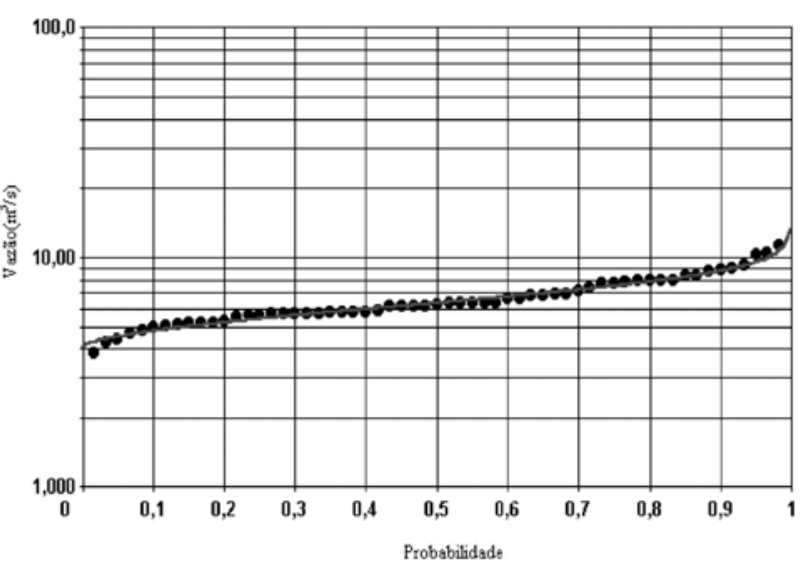

Figura 2 - Ajuste do modelo de Weibull aos dados das vazões mínimas de 7 dias de duração - Estação Acaiaca-Jusante

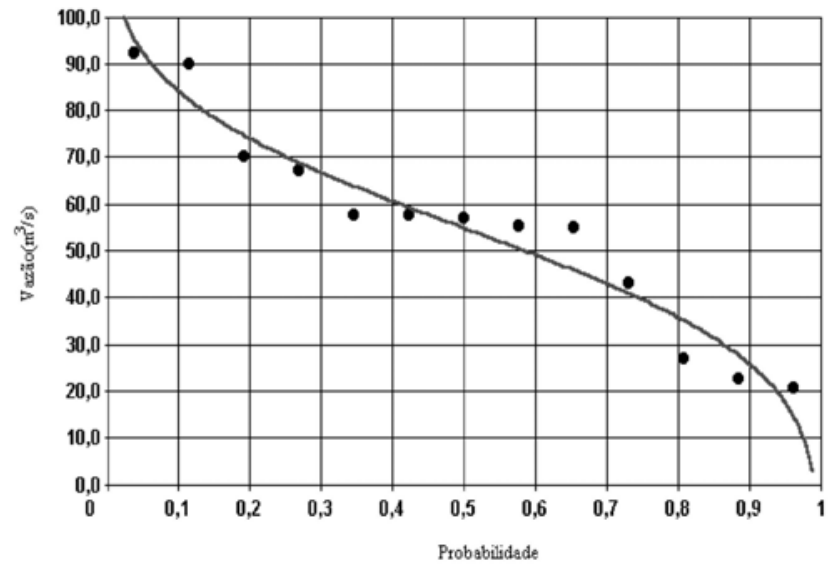

Figura 3 - Ajuste do modelo de probabilidade Pearson tipo III aos dados das vazões máximas da estação Acaiaca-Jusante

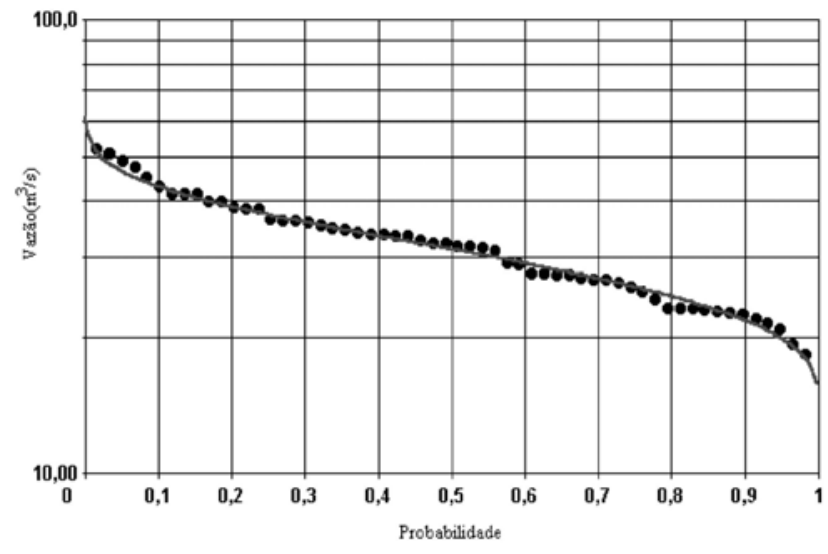

Figura 4 - Ajuste do modelo de Weibull aos dados das vazões médias da estação Acaiaca-Jusante

$\mathrm{L}=$ comprimento do talvegue;

$\mathrm{D}=$ densidade de drenagem;

$\mathrm{S}=$ declividade do curso d'água principal;

$\mathrm{P}_{\text {tot }}=$ total anual precipitado;

$\mathrm{P}_{\text {máx }}=$ chuva máxima diária; $\mathrm{e}$

$\mathrm{P}_{\text {sem+ch }}^{\text {max }}=$ total precipitado no semestre mais chuvoso.

Os resultados das regressóes e a qualidade dos ajustes para a região homogênea caracterizada pela bacia hidrográfica do rio do Carmo, são apresentados nas Tabelas 4, 5 e 6, para as vazōes mínimas, máximas e médias, respectivamente. Nestas tabelas, para cada recorrência $\mathrm{Tr}$, são apresentadas todas as equaçôes cujos ajustes atenderam ao critério de significância inferior a 5\%, medido pelo teste F. Além dos valores dos coeficientes obtidos da análise de regressão $\left(\mathrm{B}_{0}\right.$ e $\left.\mathrm{B}_{1}\right)$, as tabelas trazem ainda os coeficientes de determinação $\left(\mathrm{r}^{2}\right)$, os erros-padrão (e.p.) e as significâncias, em porcentagem, medidas pelo teste F. Para as equaçôes apresentadas nas tabelas, é dado $\mathrm{em} \mathrm{m}^{3} /\left(\mathrm{s} \times \mathrm{km}^{2}\right)$, as chuvas em mm, as áreas de drenagem em $\mathrm{km}^{2}$ e a densidade de drenagem $\mathrm{em} \mathrm{km}^{-1}$.

\section{DISCUSSÃO}

As chuvas empregadas na análise de regressão foram obtidas pela aplicação do método de Thiessen, que transformou os valores pontuais em médias nas áreas de drenagem.

Os melhores modelos de regressão relacionando as variáveis da Eq. (1) foram o linear e o potencial. Para verificar a adequação do ajuste de cada um dos modelos foi empregado como teste de significância o teste $F$ e, ainda, foram feitas avaliaçóes do coeficiente de determinação e do erro padrão. Como critério de seleção, foram aceitos os modelos com significância menor ou igual a 5\%.

Para evitar a superparametrização, considerando-se a existência de apenas 4 estaçóes fluviométricas (quatro variáveis dependentes), o modelo da Eq. (1) foi aplicado repetidas vezes, tomando-se somente uma variável independente de cada vez.

As vazões específicas mínimas apresentaram boas correlações com a área de drenagem, a precipitação total anual, a precipitação do semestre mais chuvoso e, inesperadamente, com a precipitação máxima diária.

Para as vazões máximas, as melhores correlaçōes foram com a área, a densidade de drenagem e as precipitaçóes total anual e do semestre mais chuvoso. Para a recorrência de 10 anos, não foi possível regionalizar as máximas com significância, medida pelo teste F, inferior $5 \%$. Somente para este caso, a equação foi apresentada em termos de duas variáveis independentes.

Já para as vazões específicas médias de longo período, as boas correlaçóes ocorreram com a área de drenagem, o comprimento do talvegue, a densidade de drenagem e com as precipitaçóes total anual, do semestre mais chuvoso e máxima diária. 
Tabela 4 - Modelos de regressão para a vazão mínima de sete dias de duração e recorrências entre 2 e 100 anos

\begin{tabular}{lcccccc}
\hline Equação & $\mathrm{Tr}$ & $\mathrm{B}_{0}$ & $\mathrm{~B}_{1}$ & $\mathrm{r}^{2}$ & e.p. & $\% \mathrm{~F}$ \\
\hline $\mathrm{q}_{\text {mín }}=\mathrm{B}_{0}+\mathrm{B}_{1} \mathrm{P}_{\text {sem+ch }}$ & 2 & $-0,01056$ & 0,000017 & 0,949208 & 0,000456 & 2,57 \\
$\mathrm{q}_{\text {mín }}=\mathrm{B}_{0}+\mathrm{B}_{1} \mathrm{P}_{\text {tot }}$ & 2 & $-0,01052$ & 0,000015 & 0,917627 & 0,000581 & 4,21 \\
$\mathrm{q}_{\text {mín }}=\mathrm{B}_{0} \cdot \mathrm{P}_{\text {sem+ch }}^{\mathrm{B}_{1}}$ & 2 & $5,36 \times 10^{-9}$ & 2,035176 & 0,960500 & 1,040667 & 1,99 \\
$\mathrm{q}_{\text {mín }}=\mathrm{B}_{0}+\mathrm{B}_{1} \mathrm{P}_{\text {sem+ch }}$ & 5 & $-0,01140$ & 0,000016 & 0,927267 & 0,000518 & 3,71 \\
$\mathrm{q}_{\text {mín }}=\mathrm{B}_{0}+\mathrm{B}_{1} \mathrm{P}_{\text {tot }}$ & 5 & $-0,01143$ & 0,000014 & 0,902691 & 0,000600 & 4,99 \\
$\mathrm{q}_{\text {mín }}=\mathrm{B}_{0} \cdot \mathrm{P}_{\text {sem+ch }}^{\mathrm{B}_{1}}$ & 5 & $2,96 \times 10^{-10}$ & 2,409947 & 0,945058 & 1,057726 & 2,79 \\
$\mathrm{q}_{\text {mín }}=\mathrm{B}_{0} \cdot \mathrm{P}_{\text {tot }}^{\mathrm{B}_{1}}$ & 5 & $1,87 \times 10^{-10}$ & 2,422175 & 0,918823 & 1,070598 & 4,14 \\
$\mathrm{q}_{\text {mín }}=\mathrm{B}_{0}+\mathrm{B}_{1} \mathrm{P}_{\text {máx }}$ & 10 & $-0,01380$ & 0,000273 & 0,936489 & 0,000493 & 3,23 \\
$\mathrm{q}_{\text {mín }}=\mathrm{B}_{0} \cdot \mathrm{P}_{\text {tot }}^{\mathrm{B}_{1}}$ & 10 & $1,41 \times 10^{-11}$ & 2,761224 & 0,911615 & 1,084876 & 4,52 \\
$\mathrm{q}_{\text {mín }}=\mathrm{B}_{0} \cdot \mathrm{P}_{\text {sem+ch }}^{\mathrm{B}_{1}}$ & 10 & $2,77 \times 10^{-11}$ & 2,725379 & 0,922753 & 1,079135 & 3,94 \\
$\mathrm{q}_{\text {mín }}=\mathrm{B}_{0} \cdot \mathrm{P}_{\text {máx }}^{\mathrm{B}_{1}}$ & 10 & $1,79 \times 10^{-8}$ & 2,970013 & 0,918607 & 1,081314 & 4,16 \\
$\mathrm{q}_{\text {mín }}=\mathrm{B}_{0}+\mathrm{B}_{1} \mathrm{P}_{\text {máx }}$ & 20 & $-0,01565$ & 0,000288 & 0,969010 & 0,000357 & 1,56 \\
$\mathrm{q}_{\text {mín }}=\mathrm{B}_{0} \cdot \mathrm{P}_{\text {máx }}^{\mathrm{B}_{1}}$ & 20 & $2,25 \times 10^{-9}$ & 3,422881 & 0,948941 & 1,072733 & 2,59 \\
$\mathrm{q}_{\text {mín }}=\mathrm{B}_{0}+\mathrm{B}_{1} \mathrm{P}_{\text {máx }}$ & 50 & $-0,01789$ & 0,000309 & 0,992167 & 0,000190 & 0,39 \\
$\mathrm{q}_{\text {mín }}=\mathrm{B}_{0} \cdot \mathrm{P}_{\text {máx }}^{\mathrm{B}_{1}}$ & 50 & $1,58 \times 10^{-10}$ & 4,008259 & 0,974748 & 1,058707 & 1,27 \\
$\mathrm{q}_{\text {mín }}=\mathrm{B}_{0}+\mathrm{B}_{1} \mathrm{P}_{\text {máx }}$ & 100 & $-0,01935$ & 0,000323 & 0,998759 & 0,000079 & 0,062 \\
$\mathrm{q}_{\text {mín }}=\mathrm{B}_{0} \cdot \mathrm{P}_{\text {máx }}^{\mathrm{B}_{1}}$ & 100 & $2,52 \times 10^{-11}$ & 4,415215 & 0,985928 & 1,047750 & 0,71 \\
\hline
\end{tabular}

Tabela 5 - Modelos de regressão para a vazão máxima e recorrências entre 2 e 100 anos

\begin{tabular}{|c|c|c|c|c|c|c|c|}
\hline Equação & $\operatorname{Tr}$ & $\mathrm{B}_{0}$ & $\mathrm{~B}_{1}$ & $\mathrm{r}^{2}$ & e.p. & $\% \mathrm{~F}$ & \\
\hline $\mathrm{q}_{\text {máx }}=\mathrm{B}_{0} \cdot \mathrm{A}^{\mathrm{B}_{1}}$ & 2 & 1,269193 & $-0,30887$ & 0,971786 & 1,050327 & 1,42 & \\
\hline $\mathrm{q}_{\text {máx }}=\mathrm{B}_{0}+\mathrm{B}_{1} \mathrm{D}$ & 20 & $-1,74617$ & 0,896736 & 0,903849 & 0,030137 & 4,93 & \\
\hline $\mathrm{q}_{\text {máx }}=\mathrm{B}_{0}+\mathrm{B}_{1} \mathrm{D}$ & 50 & $-3,35067$ & 1,603231 & 0,996415 & 0,009909 & 0,18 & \\
\hline $\mathrm{q}_{\text {máx }}=\mathrm{B}_{0} \cdot \mathrm{D}^{\mathrm{B}_{1}}$ & 50 & 0,001049 & 7,018514 & 0,985083 & 1,037018 & 0,75 & \\
\hline $\mathrm{q}_{\text {máx }}=\mathrm{B}_{0}+\mathrm{B}_{1} \mathrm{D}$ & 100 & $-4,75241$ & 2,216613 & 0,988232 & 0,024924 & 0,59 & \\
\hline $\mathrm{q}_{\text {máx }}=\mathrm{B}_{0} \cdot \mathrm{D}^{\mathrm{B}_{1}}$ & 100 & 0,000401 & 8,259911 & 0,978483 & 1,052901 & 1,08 & \\
\hline $\mathrm{q}_{\text {máx }}=\mathrm{B}_{0}+\mathrm{B}_{1} \mathrm{D}$ & 500 & $-8,51719$ & 3,855523 & 0,953034 & 0,088192 & 2,38 & \\
\hline $\mathrm{q}_{\text {máx }}=\mathrm{B}_{0} \cdot \mathrm{D}^{\mathrm{B}_{1}}$ & 500 & 0,000066 & 10,59274 & 0,915351 & 1,145190 & 4,33 & \\
\hline Equação* & $\operatorname{Tr}$ & $\mathrm{B} 0$ & B1 & $\mathrm{B} 2$ & $\mathrm{r} 2$ & e.p. & $\% \mathrm{~F}$ \\
\hline $\mathrm{q}_{\text {máx }}=\mathrm{B}_{0} \mathrm{D}^{\mathrm{B}_{1}} \mathrm{P}_{\mathrm{sem}+\mathrm{ch}}^{\mathrm{B}_{2}}$ & 10 & $-0,76289$ & 0,685501 & $-0,00045$ & 0,996433 & 0,005562 & 5,97 \\
\hline
\end{tabular}

"Equação com duas variáveis independentes para atender requisito pelo teste $\mathrm{F}$. 
Tabela 6 - Modelos de regressão para a vazão média de longo período de

\begin{tabular}{|c|c|c|c|c|c|c|}
\hline Equação & $\operatorname{Tr}$ & $\mathrm{B}_{0}$ & $\mathrm{~B}_{1}$ & $r^{2}$ & e.p. & $\% \mathrm{~F}$ \\
\hline $\mathrm{q}_{\mathrm{mlp}}=\mathrm{B}_{0}+\mathrm{B}_{1} \mathrm{P}_{\mathrm{sem}+\mathrm{ch}}$ & 2 & $-0,00851$ & 0,000025 & 0,984128 & 0,000362 & 0,80 \\
\hline $\mathrm{q}_{\mathrm{mlp}}=\mathrm{B}_{0}+\mathrm{B}_{1} \mathrm{P}_{\mathrm{tot}}$ & 2 & $-0,00840$ & 0,000021 & 0,948457 & 0,000653 & 2,61 \\
\hline $\mathrm{q}_{\mathrm{mlp}}=\mathrm{B}_{0} \cdot \mathrm{P}_{\mathrm{sem}+\mathrm{ch}}^{\mathrm{B}_{1}}$ & 2 & 0,000001 & 1,393828 & 0,986897 & 1,015633 & 0,66 \\
\hline $\mathrm{q}_{\mathrm{mlp}}=\mathrm{B}_{0} \cdot \mathrm{P}_{\mathrm{tot}}^{\mathrm{B}_{1}}$ & 2 & $8,5 \times 10^{-7}$ & 1,397345 & 0,954635 & 1,029283 & 2,29 \\
\hline $\mathrm{q}_{\mathrm{mlp}}=\mathrm{B}_{0}+\mathrm{B}_{1} \mathrm{P}_{\mathrm{sem}+\mathrm{ch}}$ & 5 & $-0,00409$ & 0,000026 & 0,985412 & 0,000360 & 0,73 \\
\hline $\mathrm{q}_{\mathrm{mlp}}=\mathrm{B}_{0}+\mathrm{B}_{1} \mathrm{P}_{\mathrm{tot}}$ & 5 & $-0,00397$ & 0,000022 & 0,949352 & 0,000671 & 2,57 \\
\hline $\mathrm{q}_{\mathrm{mlp}}=\mathrm{B}_{0} \cdot \mathrm{P}_{\mathrm{sem}+\mathrm{ch}}^{\mathrm{B}_{1}}$ & 5 & 0,000008 & 1,145520 & 0,986831 & 1,012863 & 0,66 \\
\hline $\mathrm{q}_{\mathrm{mlp}}=\mathrm{B}_{0} \cdot \mathrm{P}_{\mathrm{tot}}^{\mathrm{B}_{1}}$ & 5 & 0,000007 & 1,148310 & 0,954405 & 1,024067 & 2,31 \\
\hline $\mathrm{q}_{\mathrm{mlp}}=\mathrm{B}_{0}+\mathrm{B}_{1} \mathrm{P}_{\mathrm{sem}+\mathrm{ch}}$ & 10 & $-0,00158$ & 0,000026 & 0,989307 & 0,000314 & 0,54 \\
\hline $\mathrm{q}_{\mathrm{mlp}}=\mathrm{B}_{0}+\mathrm{B}_{1} \mathrm{P}_{\mathrm{tot}}$ & 10 & $-0,00153$ & 0,000022 & 0,957244 & 0,000628 & 2,16 \\
\hline $\mathrm{q}_{\mathrm{mlp}}=\mathrm{B}_{0} \cdot \mathrm{P}_{\mathrm{sem}+\mathrm{ch}}^{\mathrm{B}_{1}}$ & 10 & 0,000018 & 1,046678 & 0,990089 & 1,010166 & 0,50 \\
\hline $\mathrm{q}_{\mathrm{mlp}}=\mathrm{B}_{0} \cdot \mathrm{P}_{\mathrm{tot}}^{\mathrm{B}_{1}}$ & 10 & 0,000015 & 1,051285 & 0,961315 & 1,020183 & 1,95 \\
\hline $\mathrm{q}_{\mathrm{mlp}}=\mathrm{B}_{0}+\mathrm{B}_{1} \mathrm{P}_{\mathrm{sem}+\mathrm{ch}}$ & 20 & 0,000570 & 0,000027 & 0,992869 & 0,000260 & 0,36 \\
\hline $\mathrm{q}_{\mathrm{mlp}}=\mathrm{B}_{0}+\mathrm{B}_{1} \mathrm{P}_{\mathrm{tot}}$ & 20 & 0,000530 & 0,000023 & 0,966051 & 0,000568 & 1,71 \\
\hline $\mathrm{q}_{\mathrm{mlp}}=\mathrm{B}_{0} \cdot \mathrm{P}_{\mathrm{sem}+\mathrm{ch}}^{\mathrm{B}_{1}}$ & 20 & 0,000032 & 0,977539 & 0,993278 & 1,007797 & 0,34 \\
\hline $\mathrm{q}_{\mathrm{mlp}}=\mathrm{B}_{0} \cdot \mathrm{P}_{\mathrm{tot}}^{\mathrm{B}_{1}}$ & 20 & 0,000026 & 0,984312 & 0,969272 & 1,016745 & 1,55 \\
\hline $\mathrm{q}_{\mathrm{mlp}}=\mathrm{B}_{0}+\mathrm{B}_{1} \mathrm{P}_{\mathrm{sem}+\mathrm{ch}}$ & 50 & 0,003054 & 0,000027 & 0,995712 & 0,000205 & 0,21 \\
\hline $\mathrm{q}_{\mathrm{mlp}}=\mathrm{B}_{0}+\mathrm{B}_{1} \mathrm{P}_{\mathrm{tot}}$ & 50 & 0,002877 & 0,000023 & 0,976707 & 0,000479 & 1,17 \\
\hline $\mathrm{q}_{\mathrm{mlp}}=\mathrm{B}_{0} \cdot \mathrm{P}_{\mathrm{sem}+\mathrm{ch}}^{\mathrm{B}_{1}}$ & 50 & 0,000056 & 0,910792 & 0,995952 & 1,005624 & 0,20 \\
\hline $\mathrm{q}_{\mathrm{mlp}}=\mathrm{B}_{0} \cdot \mathrm{P}_{\mathrm{tot}}^{\mathrm{B}_{1}}$ & 50 & 0,000045 & 0,920474 & 0,979037 & 1,012844 & 1,05 \\
\hline $\mathrm{q}_{\mathrm{mlp}}=\mathrm{B}_{0}+\mathrm{B}_{1} \mathrm{P}_{\mathrm{tot}}$ & 100 & 0,004454 & 0,000024 & 0,983285 & 0,000410 & 0,84 \\
\hline $\mathrm{q}_{\mathrm{mlp}}=\mathrm{B}_{0} \cdot \mathrm{P}_{\mathrm{sem}+\mathrm{ch}}^{\mathrm{B}_{1}}$ & 100 & 0,000078 & 0,871765 & 0,996393 & 1,005079 & 0,18 \\
\hline $\mathrm{q}_{\mathrm{mlp}}=\mathrm{B}_{0} \cdot \mathrm{P}_{\mathrm{tot}}^{\mathrm{B}_{1}}$ & 100 & 0,000063 & 0,883569 & 0,9985120 & 1,010343 & 0,75 \\
\hline
\end{tabular}

\section{CONCLUSÃO}

Considerada a importância do conhecimento do escoamento superficial na bacia hidrográfica como elemento essencial para a estimativa das potencialidades e disponibilidades hídricas de seus cursos d'água, esse trabalho apresenta os modelos de regionalização das vazões máximas, mínimas de sete dias de estiagem e médias de longo período da bacia do rio do Carmo. Nos estudos é, basicamente, empregada a metodologia de regionalização hidrológica proposta pelo modelo computacional RH3.0.

Os modelos construídos consideram como variável independente a vazão específica de diferentes recorrências: de 2 a 100 anos no caso das médias e mínimas, e de 2 a 500 anos no caso das máximas.

Toda a bacia hidrográfica do rio do Carmo pode ser caracterizada como uma única região hidrologicamente homogê- nea, o que foi comprovado por meio de critérios físicos e estatísticos, baseados nas características fisiográficas e na distribuição de freqüência das vazôes adimensionalizadas.

Dos diferentes modelos de probabilidade aplicados às séries de vazões máximas, médias e mínimas, concluiu-se que a distribuição de Weibull é a que melhor explica a distribuição das médias e mínimas, enquanto a o modelo Pearson tipo III explicou melhor a distribuição das freqüências das vazões máximas. Com base nestes modelos, foram geradas as correspondentes vazões de diferentes intervalos de recorrência.

As regionalizaçôes das vazões médias, mínimas e máximas foram desenvolvidas através da metodologia clássica, considerando como variáveis independentes fatores de natureza física e climática da bacia hidrográfica e apoiando-se no programa computacional RH 3.0. Os me- lhores modelos ajustados foram do tipo linear e potencial. Considerado o pequeno número de variáveis dependentes (somente quatro estações fluviométricas), para se evitar a superparametrização, apenas uma variável independente foi considerada em cada ajuste. Foram avaliados os modelos de máximas, médias e mínimas de várias recorrências em termos das características físicas definidas pela área de drenagem, comprimento do talvegue, declividade do curso d'água e densidade de drenagem, e das características climáticas representadas pelas chuvas máxima anual, total do semestre mais chuvoso e total anual. Para converter as chuvas no ponto em chuvas espaciais, empregou-se o método de Thiessen.

Nos casos de vazões mínimas e médias, os modelos foram significativos ao nível de 5\%, medido pelo teste $\mathrm{F}$, para as variáveis climáticas representadas pela chuva total anual e total do semestre mais 
chuvoso. Neste mesmo nível de significância, para as vazóes máximas, na maioria dos casos, os modelos foram escritos em termos da densidade de drenagem.

\section{REFERÊNCIAS}

ARAÚJO, H.F. de, BARBOSA Jr., A.R.. Estudo Hidrológico da Microbacia Hidrográfica do Córrego da Agua Suja. Relatório Técnico. Departamento de Engenharia Civil/Escola de Minas/Universidade Federal de Ouro Preto, 61p., 2000.

BARBOSA Jr., A.R., SILVA, G.Q. \& CARVALHO, P.D. Regionalização de Dados Hidrológicos da Bacia do Atlantico Norte - Trecho Norte/Nordeste. Convênio Universidade Federal de Ouro preto (UFOP) e Agência Nacional de Energia Elétrica (ANEEL), p.10-100. 2002.

EUCLYDES, H.P., SOUSA, E.F. \& FERREIRA, P.A. RH 3.0 - Regionalização Hidrológica: Manual do Programa. Viçosa: UFV, DEA; Brasília; DF: MMA; Belo Horizonte, MG: RURALMINAS, 29p e 149 p., 1999.

EUCLYDES, H. P.; et al. Regionalização Hidrlógica na Bacia do Alto São Francisco a
Montante da Barragem de Três Marias, Minas Gerais. Revista Brasileira de Recurso Hídrico. Porto Alegre, n.6, p.81-105, abr./jun., 2001.

INSTITUTO BRASILEIRO DE GEOGRAFIA E ESTATÍSTICA - IBGE (2000). Disponível em: <www.ibge.gov.br/cidadesat/default.php>. Acesso em: 19 abr. 2002.

MINAS GERAIS. Agencia Técnica da Bacia do rio Doce. As Águas da bacia do rio Doce. Minas Gerais, [19-].

SANTOS, E.C.X., BARBOSA Jr., A.R. Análise de Dados de Chuva de Postos Pluviométricos da Região de Ouro Preto (MG). Relatório Técnico. Departamento de Engenharia Civil/Escola de Minas/Universidade Federal de Ouro Preto, 51p., 1999.

TUCCI, C.E.M. Hidrologia. Ciência e Aplicação. Editora da Universidade Federal do Rio Grande do Sul, Editora da Universidade de São Paulo e Associação Brasileira de Recursos Hídricos, p. 527-603., 1997.

PROJETO RADAMBRASIL. Ministério das Minas e Energia. Secretaria Geral - Folhas SF.23/ 24 Rio de Janeiro / Vitória, Levantamento de Recursos Naturais, Volume 32. Rio de Janeiro, p.20-100., 1983.
Endereço para correspondência:

Sylvio Elvis da Silva Barbosa

Estr. do Galeão, 4700

2 I 94 I -000 Rio de Janeiro - RJ -

Brasil

Tel: (2 I) 3383-9I 44

E-mail: sylviobarbosa@bol.com.br

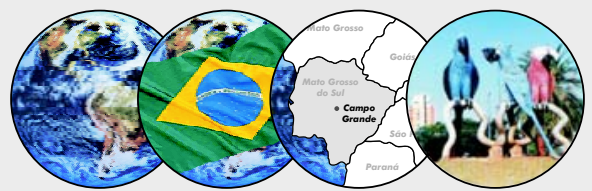 \\ $23^{\circ}$ Congresso Brasileiro de Engenharia Sanitária e Ambiental
}

\author{
Saneamento Ambiental no Brasil: \\ Utopia ou Realidade?
}

Data: 18 a 23 de setembro de 2005

Local: Centro de Exposições Albano Franco Campo Grande - MS 